\title{
(6) OPEN ACCESS \\ Influence of chronic diseases on societal participation in paid work, volunteering and informal caregiving in Europe: a 12-year follow-up study
}

\author{
Micky Scharn, ${ }^{1}$ Karen Oude Hengel, ${ }^{2,3,4}$ Cécile R L Boot, ${ }^{1,4}$ Alex Burdorf, ${ }^{2}$ \\ Merel Schuring, ${ }^{2}$ Allard J van der Beek, ${ }^{1,4}$ Suzan J W Robroek ${ }^{2}$
}

\begin{abstract}
'Department of Public and Occupational Health, Amsterdam Public Health Research Institute, Amsterdam UMC, VU University Amsterdam, Amsterdam, The Netherlands ${ }^{2}$ Department of Public Health, Erasmus MC University Medical Center, Rotterdam, The Netherlands

${ }^{3}$ Netherlands Organization for Applied Scientific Research TNO, Leiden, The Netherlands

4Body@Work, Research Center on Work, Health and Technology, Amsterdam, The Netherlands
\end{abstract}

\section{Correspondence to}

Suzan J W Robroek, Department of Public Health, Erasmus MC, Rotterdam 3000 CA, The Netherlands; s.robroek@ erasmusmc.n

Received 29 May 2018 Revised 16 October 2018 Accepted 19 October 2018 Published Online First 26 November 2018

\section{Check for updates}

(c) Author(s) (or their employer(s)) 2019. Re-use permitted under CC BY-NC. No commercial re-use. See rights and permissions. Published by BMJ.

To cite: Scharn $M$

Oude Hengel $\mathrm{K}$, Boot CRL,

et al. J Epidemiol Community Health 2019:73:136-141.

\begin{abstract}
Background This study aims to provide insight into (1) the associations between having a chronic disease and participation in paid work, volunteer activities or informal care, (2) the associations between the onset of a chronic disease and these forms of societal participation, and (3) whether these associations differ across educational leve and gender.

Methods The study population consisted of $n=21875$

respondents of the Survey of Health, Ageing and

Retirement in Europe aged between 50 years and the country-specific retirement age. The influence of having and the onset of a chronic disease on societal participation was analysed using a hybrid Poisson regression model, combining fixed and random effects, and presented by relative risks (RRs).
\end{abstract}

Results Individuals with a chronic disease were less likely to participate in paid work (RR: $0.69 ; 95 \% \mathrm{Cl} 0.67$ to 0.71 ) and volunteer activities (RR: $0.92 ; 95 \% \mathrm{Cl} 0.88$ to 0.97 ), but more likely to give informal care (RR: 1.05; $95 \% \mathrm{Cl} 1.01$ to 1.08). Onset of a chronic disease was associated with a higher likelihood to quit paid work (RR: $0.91 ; 95 \% \mathrm{Cl} 0.86$ to 0.97 ) and to give informal care (RR: $1.08 ; 95 \% \mathrm{Cl} 1.01$ to 1.16). Lower educated individuals with a chronic disease or with the onset of a chronic disease were less likely to have paid work than higher educated individuals.

Conclusion Individuals with a chronic disease were less likely to participate in paid work and volunteer activities, and more likely to provide informal care. Educational inequalities were present for paid work. More insight into which factors hinder societal participation among individuals with a chronic disease is needed.

\section{INTRODUCTION}

The European population is ageing due to a decline in birth rates and increasing life expectancy. In Europe, per 100 persons of working age (15-64 years), 29.9 persons are aged 65 years and over. In order to keep the social security programmes sustainable and increase the proportion of older individuals in the labour force, benefit levels were reduced, early retirement schemes were adjusted or abolished, and the official retirement age was raised. ${ }^{2}$ In 2011, one-third of the working-age population of the European Union had a chronic disease. ${ }^{3}$ As a result of the increasing retirement age, the prevalence of chronic diseases within the working-age population is expected to further increase. ${ }^{45}$ Having chronic diseases might lead to ill health or limitations in physical or mental functioning. ${ }^{67}$ This might have consequences for participation in society. Societal participation can be seen as performing activities that are of benefit to individuals, groups or the society as a whole. ${ }^{8}$ Having paid work, performing volunteer activities and informal caregiving are considered typical forms of societal participation.

Previous research has shown that individuals with a chronic disease are less often involved in paid work as they are more likely to become unemployed or to receive work disability benefits. Besides limitations in functioning, one study found that individuals who were afraid that their health limited their ability to work reported less productivity at work or even exit from work. ${ }^{10}$

For other forms of societal participation, such as volunteer activities and informal caregiving, the impact of chronic diseases is less clear. Previous studies have found a negative association or no association between having a chronic disease and volunteer activities. ${ }^{1112}$ A lack of knowledge exists regarding the influence of having a chronic disease on informal caregiving. On the one hand, individuals with a chronic disease might be less able to give informal care due to their health problems. ${ }^{13}$ On the other hand, they might feel more competent about their knowledge and skills to give informal care than healthy individuals. ${ }^{13}$ So far, most studies have used a cross-sectional design, which hampers a clear insight into how having a chronic disease will influence participation in volunteer activities or volunteer work.

In addition to the presence of a chronic disease, demographic factors might influence societal participation. Previous research has shown that lower educated individuals are more likely to have a chronic disease and are also less likely to participate in society than higher educated individuals. $^{9111314}$ Workers with lower educational levels have an increased risk of health-related exit from paid work. ${ }^{15}$ One study found that workers with a combination of low socioeconomic status and presence of a cardiovascular disease were at a particularly high risk of exit from paid work by disability benefit. ${ }^{16}$ Women are more likely to have a chronic disease and are less likely to have paid work than men. ${ }^{17} 18$

Most studies concerning the effects of chronic diseases on societal participation, in particular on having paid work, have been primarily based on 
individuals with and without chronic diseases. ${ }^{9}$ However, this design might lead to biased results because individuals who have a chronic disease might differ in (un)observed covariates from individuals without a chronic disease. Fixed-effects models can estimate effects by making comparisons within individuals, and thereby eliminate the effects of confounding variables. ${ }^{19}$ The current study combines random and fixed effects in a hybrid model to analyse both differences in societal participation among and the influence of the onset of a chronic disease on the three forms of societal participation (fixed effects).

This study aims to provide insight into (1) the associations between having a chronic disease and participation in paid work, volunteer activities or informal caregiving, (2) the associations between the onset of a chronic disease and these forms of societal participation, and (3) whether these associations differ across educational level and gender.

\section{METHODS}

\section{Study design}

The study population was selected from the Survey of Health, Ageing and Retirement in Europe (SHARE). SHARE is a longitudinal study of individuals aged 50 years and older across Europe and Israel. The sampling procedure differed between countries. The measurements for 2004, 2006, 2010, 2013 and 2015 were included for the present study. More information on SHARE has been described elsewhere. ${ }^{20} 21$

\section{Study population}

Figure 1 shows the flow diagram of the study population. First, individuals were included if they lived in Europe and participated in at least two waves $(\mathrm{n}=79841)$, meaning that individuals living in Austria, Belgium, Czech Republic, Denmark, Estonia, France, Germany, Greece, Ireland, Italy, Luxembourg, the Netherlands, Poland, Portugal, Slovenia, Spain, Sweden or Switzerland were included. Second, analyses were restricted to 27058 individuals who were aged between 50 years and the country-specific retirement age in 2004. ${ }^{22}$ Third, individuals with a chronic disease, without a chronic disease and those who developed a chronic disease during follow-up were included $(n=23132)$, thereby excluding the observations from those who changed from having a chronic disease to not having a chronic disease (except for the sensitivity analyses). Lastly, individuals were included if they had information on societal participation, presence of a chronic disease and confounders $(\mathrm{n}=22011)$. In total, 21875 individuals were included in the final model as individuals were only included if they had information on the three forms of social participation in the same waves.

\section{Societal participation}

Participation in paid employment was assessed using the queswere having paid work (including self-employed), unemployed, disabled, retired, taking care of family and other. The question was dichotomised into 'paid work' and 'no paid work'.

Participation in volunteer activities was assessed using the question 'Did you participate in one or more of the following activities in the last month?' In case the option 'charity or voluntary work' was answered with 'yes', the person was considered to participate in volunteer activities. From wave 4 and onwards from 'last month' to 'last 12 months'. individuals with and without a chronic disease (random effects) tion 'What is your current job situation?' Response options (2012, 2014, 2016), the time frame of this question changed

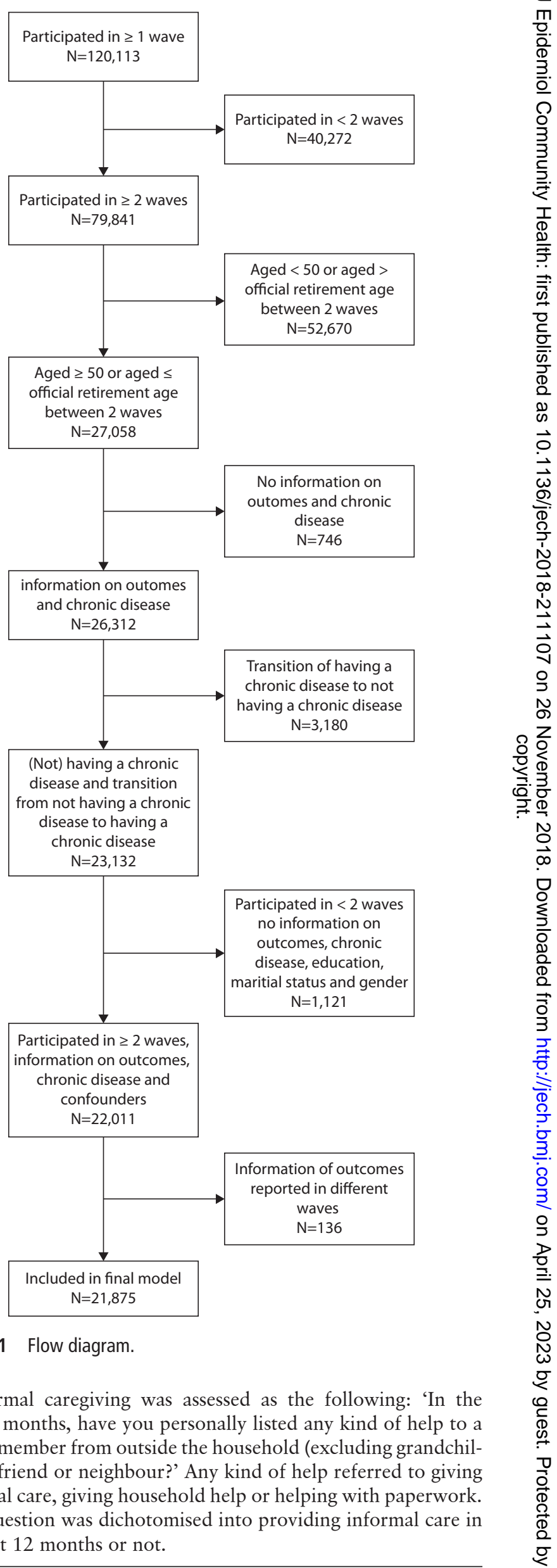

Scharn M, et al. J Epidemiol Community Health 2019;73:136-141. doi:10.1136/jech-2018-211107 


\section{Chronic disease}

Presence of a chronic disease was asked as the following: 'Some people suffer from chronic or long-term health problems. By chronic or long-term we mean it has troubled you over a period of time or is likely to affect you over a period of time. Do you have any such health problems, illness, disability or infirmity? Individuals could answer 'yes' or 'no'.

\section{Demographic factors}

Gender, age, education and marital status were included as demographic factors. Education was coded according to the 1997 International Standard Classification of Education and categorised into low (preprimary, primary and lower secondary), intermediate (upper secondary) and high (postsecondary) education. Marital status was dichotomised into living with or without a partner. Marital status was only measured at baseline, except when marital status changed during follow-up. If marital status was missing, marital status was imputed from the previous wave.

\section{Analyses}

Descriptive statistics of the study population were based on individuals' first included observation. The correlation coefficients between the three outcome variables were analysed using Spearman.

A hybrid Poisson regression model for repeated measurements was used, also known as within-between model. This model allows to separately analyse the influence of having a chronic disease and the onset of a chronic disease on societal participation. An advantage of this model is that the within-individual part removes the effects of (unknown) time-invariant variables, resulting in no omitted-variable bias. The between-individual part, on the other hand, measures the effect of variables that do not change over time, such as having a chronic disease and gender, and allows coefficients to vary between individuals by also taking into account variables that do change over time. ${ }^{19}$ This means that that the hybrid model has both a between-individuals and within-individual regression. ${ }^{19} 2324$ The between-individuals regression coefficient provided insight into the differences in societal participation between individuals with and without a chronic disease, while the within-individual regression coefficient showed the influence of the onset of a chronic disease on changes in the three types of societal participation between two waves. ${ }^{23} 24$ A random factor for each participant was added to the model to take into account the dependence of the multiple observations for each person. A random factor for country was also added to take into account that individuals from the same country are more like each other than those from another country. Furthermore, a dummy variable for each wave was added to take into account time trends. Since the prevalence of having paid work was relatively high $(>10 \%)$, the associations were presented as relative risks (RR), calculated as a risk ratio. ${ }^{25}$ First, crude hybrid models were performed for associations between chronic disease and each outcome separately. Next, the hybrid models were adjusted for (1) demographic characteristics and (2) the two other forms of societal participation.

The following hybrid Poisson regression model was used:

$\mathrm{y}_{\text {it }}=\beta_{\text {onset }}\left(\mathrm{X}_{\mathrm{it}}-\mathrm{X}_{\mathrm{i}}\right)+\beta_{\text {having }} \mathrm{X}_{\mathrm{i}}+\beta_{\text {wave }}+\mathrm{u}_{\mathrm{i}}+\mathrm{u}_{\mathrm{c}}+\gamma_{\mathrm{zi}}+\varepsilon_{\mathrm{it}}$

in which $y_{\text {it }}$ is either paid work, volunteer activities or informal caregiving for individual $\mathrm{i}$ at time $\mathrm{t} ; \beta_{\text {onset }}$ is the regression coefficient for onset of a chronic disease, describing how the change of not having a chronic disease to having a chronic disease between waves will affect societal participation in that period within individuals (calculated by $\mathrm{X}_{\mathrm{it}}$ as the presence of a chronic disease of participant $i$ at measurement $t$ minus $X_{i}$ as the mean value of the chronic disease averaged across all measurements within each participant); $\beta_{\text {having }}$ is the regression coefficient for having a chronic disease; $\beta_{\text {wave }}$ is the regression coefficient for the subsequent waves; $u_{i}$ is the individual random factor; $u_{c}$ is the country random factor; $\gamma_{\mathrm{zi}}$ is the confounder; and $\varepsilon_{\mathrm{it}}$ is the error term. ${ }^{23}$

In case of statistically significant interaction for education and gender $(\mathrm{p}<0.05)$, analyses were stratified by these factors. For the stratified analyses, the level of education at baseline was used.

Furthermore, sensitivity analyses were performed to investigate whether the results differed when individuals with a transition from having a chronic disease to not having a chronic disease were included. Descriptive statistics and correlations were conducted using SPSS V.22 and the other analyses were conducted using R V.i386 3.4.2.

\section{RESULTS}

Table 1 shows the baseline characteristics of the study population. Of the individuals with paid work, volunteer

Table 1 Description of study population at baseline

\begin{tabular}{|c|c|c|c|c|c|c|}
\hline & \multicolumn{2}{|c|}{ Paid work $n=14582$} & \multicolumn{2}{|c|}{ Volunteer activities $n=3824$} & \multicolumn{2}{|c|}{ Informal caregiving $n=8681$} \\
\hline & Mean (SD) & $\%$ & Mean (SD) & $\%$ & Mean (SD) & $\%$ \\
\hline Having a chronic disease at enrolment & & 26.3 & & 33.6 & & 35.4 \\
\hline Onset of a chronic disease during follow-up & & 22.5 & & 21.9 & & 22.8 \\
\hline \multicolumn{7}{|l|}{ Demographic factors } \\
\hline Gender: female & & 46.9 & & 51.9 & & 54.4 \\
\hline Age (years) & $54.6(3.2)$ & & $55.2(3.4)$ & & $55.0(3.4)$ & \\
\hline \multicolumn{7}{|l|}{ Education } \\
\hline Low & & 24.6 & & 19.6 & & 25.5 \\
\hline Intermediate & & 37.3 & & 34.9 & & 37.1 \\
\hline High & & 38.1 & & 45.4 & & 37.4 \\
\hline Marital status: having no partner & & 21.3 & & 21.2 & & 21.9 \\
\hline \multicolumn{7}{|l|}{ Societal participation } \\
\hline Paid work & & 100 & & 68.5 & & 69.3 \\
\hline Volunteer activities & & 18.0 & & 100 & & 23.7 \\
\hline Informal caregiving & & 41.3 & & 53.8 & & 100 \\
\hline
\end{tabular}


Table 2 Influence of having a chronic disease and the onset of a chronic disease on different types of societal participation (individuals $\mathrm{n}=21875$; countries $n=17$ )

\begin{tabular}{|c|c|c|c|c|c|c|}
\hline & \multicolumn{2}{|c|}{ Having paid work } & \multicolumn{2}{|c|}{ Having volunteer activities } & \multicolumn{2}{|c|}{ Informal caregiving } \\
\hline & RR & $95 \% \mathrm{Cl}$ & $\mathbf{R R}$ & $95 \% \mathrm{Cl}$ & $\mathbf{R R}$ & $95 \% \mathrm{Cl}$ \\
\hline \multicolumn{7}{|c|}{ Having a chronic disease } \\
\hline Crude model & 0.65 & 0.59 to 0.73 & 0.90 & 0.85 to 0.94 & 1.01 & 0.98 to 1.04 \\
\hline Adjusted model* & 0.69 & 0.67 to 0.71 & 0.97 & 0.91 to 1.00 & 1.03 & 1.00 to 1.07 \\
\hline Final modelt & 0.69 & 0.67 to 0.71 & 0.92 & 0.88 to 0.97 & 1.05 & 1.01 to 1.08 \\
\hline \multicolumn{7}{|c|}{ Onset of a chronic disease } \\
\hline Crude model & 0.76 & 0.72 to 0.80 & 1.00 & 0.92 to 1.09 & 1.02 & 0.96 to 1.10 \\
\hline Adjusted model ${ }^{*}$ & 0.91 & 0.87 to 0.96 & 0.98 & 0.90 to 1.07 & 1.07 & 1.00 to 1.15 \\
\hline Final model $†$ & 0.91 & 0.86 to 0.97 & 0.98 & 0.89 to 1.08 & 1.08 & 1.01 to 1.16 \\
\hline
\end{tabular}

Numbers depicted in bold are statistically significant $(p<0.05)$.

${ }^{*}$ Adjusted models were adjusted for demographic factors (gender, age, education and marital status).

tFinal models were adjusted for demographic factors and two other forms of societal participation.

$\mathrm{RR}$, relative risk.

activities or informal caregiving at baseline, respectively, $26.3 \%(n=3834), 33.6 \%(n=1283)$ and $35.4 \%(n=3077)$ had a chronic disease and $22.5 \%(\mathrm{n}=3277), 21.9 \%(\mathrm{n}=838)$ and $22.8 \%(n=1977)$ had an onset of a chronic disease during follow-up. The majority $(n=14528)$ of the individuals had paid work, $n=3824$ had volunteer activities and $\mathrm{n}=8681$ provided informal care at baseline. Of all participants, 4191 individuals did not participate in any of the three forms (ie, paid work, volunteer activities and informal caregiving), whereas 627 individuals participated in all three forms at baseline. The correlation between the three participation measures was low (Spearman's $\mathrm{r}<0.15$ ).

Table 2 shows that individuals with a chronic disease were less likely to have paid work (RR: 0.69) and volunteer activities (RR: 0.92) compared with those without a chronic disease. However, individuals with a chronic disease were more likely to give informal care compared with those without a chronic disease (RR: 1.05). Additional analyses showed a statistically significant interaction of having paid work and having a chronic disease with giving informal care. Individuals with paid work and with a chronic disease were more likely to give informal care than individuals without a chronic disease in paid work (RR: $1.11 ; 95 \%$ CI 1.07 to 1.16$)$. Individuals with a chronic disease but without paid work were less likely to give informal care (RR: 0.94 ; $95 \%$ CI 0.88 to 0.99 ) than individuals without a chronic disease and paid work. Individuals with an onset of a chronic disease between two waves were less likely to remain in paid work during that period (RR: 0.91), but were more likely to give informal care during that period, compared with themselves in other periods (RR: 1.08).

A statistically significant interaction was found between educational level and chronic disease for having paid work. All other interaction terms were not statistically significant. Table 3 shows that lower educated individuals with a chronic disease had a $45 \%$ higher probability to be out of paid work than higher educated individuals with a chronic disease (RR: 0.80 for high educated individuals and RR: 0.55 for low educated individuals). The onset of a chronic disease and the likelihood to quit paid work were statistically significant for intermediate (RR: 0.90 ) and low (RR: 0.88) education.

The results of the sensitivity analyses, in which also individuals with a transition from a chronic disease to no chronic disease were included, were in line with the results in table 2 . The RRs differed less than $5.5 \%$ from the presented results.

\section{DISCUSSION}

Individuals with a chronic disease were less likely to participate in paid work and volunteer activities compared with individuals without a chronic disease. Unexpectedly, they were more likely to give informal care than those without a chronic disease. Individuals with onset of a chronic disease were less likely to participate in paid work. Besides, individuals with onset of a chronic disease became more active in informal caregiving. Among lower educated workers, the adverse effects of a chronic disease on paid work were stronger than among higher educated workers. Educational inequalities for paid work were present for onset of a chronic disease as well.

\section{Participation in paid work}

Our findings regarding the effects of having a chronic disease on having paid work are in line with previous studies. 9142627 Individuals with a chronic disease might have more difficulties to participate in paid work due to functional limitations or lower psychosocial resources. ${ }^{67}$ Workers with a chronic disease are therefore more vulnerable to exit paid employment through work disability pension or unemployment. ${ }^{9}$

This is the first study that showed that the onset of a chronic disease is associated with a lower likelihood of participation in paid work. Furthermore, the regression coefficients were

Table 3 Associations of having a chronic disease and onset of a chronic disease on having paid work stratified by educational level $(n=21875)$

\begin{tabular}{lll}
\hline Having paid work & & \\
\hline & RR & $95 \% \mathrm{Cl}$ \\
\hline $\begin{array}{l}\text { Having a chronic disease } \\
\text { Low education ( } \mathrm{n}=6993)\end{array}$ & 0.55 & 0.52 to 0.59 \\
$\quad$ Intermediate education ( $\mathrm{n}=8005)$ & 0.67 & 0.64 to 0.71 \\
$\quad$ High education ( $\mathrm{n}=6877)$ & 0.80 & 0.76 to 0.83 \\
Onset of a chronic disease & & \\
$\quad$ Low education ( $\mathrm{n}=6993)$ & 0.88 & 0.87 to 0.99 \\
Intermediate education ( $\mathrm{n}=8005)$ & 0.90 & 0.82 to 0.99 \\
High education ( $\mathrm{n}=6877)$ & 0.95 & 0.87 to 1.04 \\
\hline
\end{tabular}

Numbers depicted in bold are statistically significant $(\mathrm{p}<0.05)$.

*Model was adjusted for gender, age, marital status, volunteer work and informal care. $\mathrm{RR}$, relative risk. 
stronger for having a chronic disease than for onset of a chronic disease. An explanation is that onset of a chronic disease is an acute change, while having a chronic disease is both an acute and a long-term change. This implies that the influence of the onset of a chronic disease on labour force participation may well extend beyond two waves.

Lower educated individuals with a chronic disease were even less likely to have paid work compared with those with higher education and a chronic disease. Furthermore, intermediate and low educated individuals with the onset of a chronic disease were more likely to quit paid employment. Lower educated workers generally have a higher physical workload and lower job control than higher educated workers, whereby those with a chronic disease probably face more difficulties in combining their disease with their work tasks. ${ }^{28} 29$

\section{Participation in volunteer activities}

Few studies investigated the association between having a chronic disease and performing volunteer activities. ${ }^{11}{ }^{12}$ It was expected that participation in volunteer activities was an alternative for individuals with a chronic disease when participation in paid work was not possible, since volunteer activities are more flexible and require less commitment. ${ }^{30}$ On the other hand, individuals with paid work experience a higher social status. This might lead to a higher level of identification to a collective identity and thus lead to less difficulties to participate in activities outside the labour market, such as volunteer activities. ${ }^{31}$

Onset of a chronic disease was not associated with having volunteer activities. Due to flexibility and commitment, it might be the case that individuals with the onset of a chronic disease put volunteer activities on hold, while not having consequences for their volunteer activity status yet.

\section{Participation in informal care}

Individuals with a chronic disease and those with an onset of a chronic disease were more likely to give informal care. Individuals with a chronic disease might be more likely to give informal care to others because they know which care to give or are better able at helping with paperwork to apply for help. A previous study found that about a third of Europeans aged 50 years or older help others with household tasks or personal care, ${ }^{13}$ while in the present study $40 \%$ of the individuals provided informal care. This might be explained by the broader concept of informal caregiving (giving personal care, giving household help or helping with paperwork) used in the present study. If a stricter concept of informal caregiving (help with personal care or help with household tasks) would have been used, the prevalence of informal caregiving might have been lower. On the other hand, the question on informal care did not take into account caregiving between partners, meaning that some informal caregiving might have been missed. However, informal caregiving to partners is not always recognised as informal care and individuals of 50 years and over give most care to parents, and we do not expect a major bias because of this. ${ }^{12} 13$

\section{Strengths and limitations}

The strengths of the present study are its longitudinal design and that both having a chronic disease and onset of a chronic disease were analysed in one model. Another strength is the inclusion of different forms of societal participation. The present study showed that the strengths of the associations between having a chronic disease and participation in paid work, volunteer activities or informal caregiving differed, which emphasised that a summarised outcome of overall societal participation has drawbacks. It has been suggested that individuals may experience different benefits from different types of societal participation, and that individuals might even receive energy from participation in more than one form of societal participation. ${ }^{32}$ Some limitations should be considered as well. First, since $65.4 \%$ of the individuals participated only twice in SHARE, causality or reversed causality could not be investigated with a time-lag model. In other words, it was not possible to distinguish between cause and consequences. Second, the time frame of assessing volunteer activities changed from 'last month' to 'last year' between wave 2 and wave 4 . As a consequence, $14.8 \%$ and $15.6 \%$, respectively, participated in volunteer activities in the first two waves, while in the last three waves this increased to $20.1 \%, 20.5 \%$ and $19.4 \%$, respectively. This might mean that individuals are more likely to participate once or a few times per year in volunteer activities instead of participating in volunteer activities on a monthly basis. Third, data from wave 3 (SHARELIFE) were excluded from the current study because this wave focused on people's life histories. This means that the years 2008 and 2009 were not covered, resulting in less observations per person. Since the time frame of the questions referred to the current moment and up to the past year, it is not likely that the exclusion of SHARELIFE has biased the results of the current study. Furthermore, having a chronic disease was self-reported and very broadly assessed. Moreover, it is unknown whether the disease was confirmed by a doctor. Therefore, individuals might have different views concerning whether a health problem is a chronic disease or not. Fifth, the official retirement age was based on the country-specific retirement age during the first wave of SHARE (2004). Nowadays, the official retirement age is higher in most European countries. However, most often this is a gradual process and therefore no major differences in outcomes are expected. Finally, SHARE provides opportunities to focus on cross-national differences. Unfortunately, our study population was too small for evaluation of country differences. Thus, we were unable to evaluate the influence of, for example, social security system and economic climate on the generalisability of our findings to individual countries. Larger studies are required to address cross-national differences in the determinants of societal participation.

The results of this longitudinal study showed that having a chronic disease reduced participation in paid work and volunteer activities, but increased participation in informal caregiving. Moreover, individuals with an onset of a chronic disease had a higher likelihood of quitting paid work and were more likely to give informal care. Educational inequalities were observed for paid work for both having and onset of a chronic disease. Research should focus on the underlying factors which might hinder or facilitate individuals with or the onset of a chronic disease to participate in paid work, volunteer activities and informal caregiving.

\section{What is already known on this subject}

- Individuals with a chronic disease are less likely to participate in paid work than those without a chronic disease, but the association between having a chronic disease and participation in volunteer activities or informal caregiving is not clear yet.

- No study has investigated the association between onset of a chronic disease and participation in these forms of societal participation. 


\section{What this study adds}

- Individuals with a chronic disease were less likely to have paid work and volunteer activities, but were more likely to give informal care.

- Individuals with the onset of a chronic disease were less likely to have paid work, but were more likely to give informal care.

- Lower educated individuals with a chronic disease had a lower probability to have paid work than higher educated individuals with a chronic disease.

- Low and intermediate educated individuals with the onset of a chronic disease were more likely to quit paid work than low and intermediate educated individuals without a chronic disease.

- Research should focus on the barriers and facilitators for individuals with or the onset of a chronic disease to participate in society.

Acknowledgements This paper uses data from SHARE waves 1, 2, 4, 5 and 6 (DOIs: 10.6103/SHARE.w1.600, 10.6103/SHARE.w2.600, 10.6103/SHARE.w4.600, 10.6103/SHARE.w5.600, 10.6103/SHARE.w6.600) (see Börsch-Supan et al (2013) for methodological details).

Contributors The study was conceived by MiS, $\mathrm{KOH}$ and SJWR. Statistical analyses were designed by MeS, KOH, SJWR and MiS, and undertaken by MiS. Interpretation of data was undertaken by $\mathrm{KOH}$, SJWR, MeS and MiS. KOH, SJWR and MiS produced the initial draft of the manuscript; all authors (MiS, KOH, CRLB, AB, MeS, AJvdB, SJWR) revised it critically for important intellectual content, approved the final version prepared by $\mathrm{KOH}$, SJWR and MiS, and agree to be accountable for all aspects of the work.

Funding The SHARE data collection has been primarily funded by the European Commission through FP5 (QLK6-CT-2001-00360), FP6 (SHARE-13: RII-CT-2006-062193, COMPARE: CIT5-CT-2005-028857, SHARELIFE: CIT4CT-2006-028812) and FP7 (SHARE-PREP: N²11909, SHARE-LEAP: $N^{\circ} 227822$, SHARE M4: N²61982). Additional funding from the German Ministry of Education and Research, the Max Planck Society for the Advancement of Science, the US National Institute on Aging (U01_AG09740-13S2, P01_AG005842, P01_AG08291, P30_AG12815, R21_AG025169, Y1-AG-4553-01, IAG BSR06-11, OGHA 04-064, HHSN271201300071C) and from various national funding sources is gratefully acknowledged (see http://www.share-project.org). SJWR is funded by a fellowship from the Erasmus University Rotterdam.

Competing interests None declared.

Patient consent Not required.

Ethics approval The SHARE study was reviewed and approved by the ethics committee of the University of Mannheim (until 2011) and the Ethics Council of the Max-Planck-Society for the Advancement of Science (since 2011).

Provenance and peer review Not commissioned; externally peer reviewed.

Data sharing statement The SHARE data are publicly available at http://www. share-project.org/data-access/user-registration.html. The authors of this manuscript are not authorised to provide data directly to any users.

Open access This is an open access article distributed in accordance with the Creative Commons Attribution Non Commercial (CC BY-NC 4.0) license, which permits others to distribute, remix, adapt, build upon this work non-commercially, and license their derivative works on different terms, provided the original work is properly cited, appropriate credit is given, any changes made indicated, and the use is non-commercial. See: http://creativecommons.org/licenses/by-nc/4.0/.

\section{REFERENCES}

1 Eurostat. Old-age-dependency ratio. 2016 http://ec.europa.eu/eurostat/tgm/table. do?tab=table\&init=1\&language $=$ en \&pcode=tps00198\&plugin=1 (updated 11 Aug 2016).

2 Hofäcker D, Radl J. Retirement transitions in times of institutional change: theoretical concept. In: Hofäcker D, Hess M, König S, eds. Delaying retirement. London: Palgrave Macmillan London, 2016:1-21.

3 Heide vander I, Melchiorre MG, Quattrini S, et al. Innovating care for people with multiple chronic conditions in Europe: an overview. Utrecht, 2015.
4 Rechel B, Grundy E, Robine JM, et al. Ageing in the European Union. Lancet 2013:381:1312-22.

5 Busse R, Blümel M, Scheller-Kreinsen D, et al. Tackling chronic disease in Europe: strategies, interventions and challenges. Copenhagen: World Health Organization, 2010. on behalf of European observatory on health systems and policy; 2010. Report No.: Observatory Studies Series number 20.

6 Harbers MM, Achterberg PW. Europeans of retirement age: chronic diseases and economic inactivity. Bilthoven: RIVM, 2012.

7 Boot CR, Deeg DJ, Abma T, et al. Predictors of having paid work in older workers with and without chronic disease: a 3-year prospective cohort study. J Occup Rehabil 2014;24:563-72.

8 Piškur B, Daniëls R, Jongmans MJ, et al. Participation and social participation: are they distinct concepts? Clin Rehabil 2014;28:211-20.

9 van Rijn RM, Robroek SJ, Brouwer S, et al. Influence of poor health on exit from paid employment: a systematic review. Occup Environ Med 2014;71:295-301.

10 Rodriguez-Sanchez B, Alessie RJM, Feenstra TL, et al. The relationship between diabetes, diabetes-related complications and productive activities among older Europeans. Eur J Health Econ 2018;19:719-34

11 Erlinghagen M, Hank K. The participation of older Europeans in volunteer work. Ageing Soc 2006;26:567-84.

12 Hank K, Stuck S. Volunteer work, informal help, and care among the 50+ in Europe: further evidence for 'linked' productive activities at older ages. Soc Sci Res 2008;37:1280-91.

13 Broese van Groenou MI, De Boer A. Providing informal care in a changing society. Eur J Ageing 2016;13:271-9.

14 Alavinia SM, Burdorf A. Unemployment and retirement and ill-health: a cross-sectional analysis across European countries. Int Arch Occup Environ Health 2008;82:39-45.

15 Carr E, Fleischmann M, Goldberg M, et al. Occupational and educational inequalities in exit from paid employment at older ages: Evidence from seven prospective cohort studies. Occup Environ Health 2018;75:369-77.

16 Virtanen M, Lallukka T, Ervasti J, et al. The joint contribution of cardiovascular disease and socioeconomic status to disability retirement: A register linkage study. Int J Cardiol 2017;230:222-7.

17 Carmichael F, Charles S, Hulme C. Who will care? Employment participation and willingness to supply informal care. J Health Econ 2010;29:182-90.

18 Vlassoff C. Gender differences in determinants and consequences of health and illness. J Health Popul Nutr 2007;25:47-61.

19 Firebaugh G, Warner C, Massoglia M, et al. Random effects, and hybrid models for causal analysis. Morgan SL, ed. Handbook of causal analysis for social research. Dordrecht: Springer Netherlands, 2013:113-32.

20 Börsch-Supan A, Brandt M, Hunkler C, et al. Data Resource Profile: the Survey of Health, Ageing and Retirement in Europe (SHARE). Int J Epidemiol 2013:42:992-1001.

21 Börsch-Supan A, Jürges $\mathrm{H}$. The survey of health, ageing and retirement in Europe Methodology. Mannheim: Mannheim Research Institute for the Economics of Aging (MEA), 2005

22 Administration SS, Administration ISS. Social security programs throughout the world: Europe, 2004. Washington: Social Security Administration, 2004. Contract No.: SSA Publication No. 13-11801.

23 Schuring M, Robroek SJ, Burdorf A. The benefits of paid employment among persons with common mental health problems: evidence for the selection and causation mechanism. Scand I Work Environ Health 2017:43:540-9.

24 Curran PJ, Bauer DJ. The disaggregation of within-person and between-person effects in longitudinal models of change. Annu Rev Psychol 2011:62:583-619.

25 Sedgwick P. Relative risks versus odds ratios. BMJ 2014;348:g1407.

26 Leijten FR, de Wind A, van den Heuvel SG, et al. The influence of chronic health problems and work-related factors on loss of paid employment among older workers. J Epidemiol Community Health 2015:69:1058-65.

27 Leijten FR, van den Heuvel SG, Ybema JF, et al. The influence of chronic health problems on work ability and productivity at work: a longitudinal study among older employees. Scand J Work Environ Health 2014;40:473-82.

28 Robroek SJ, Rongen A, Arts CH, et al. Educational Inequalities in Exit from Paid Employment among Dutch Workers: The Influence of Health, Lifestyle and Work. PLoS One 2015;10(8):e0134867.

29 Belin A, Zamparutti T, Tull K, et al. Occupational health and safety risks for the most vulnerable workers. Brussels, 2011. Report No.: IP/A/EMPL /ST/2010-03

30 van Campen C, Cardol M. When work and satisfaction with life do not go hand in hand: health barriers and personal resources in the participation of people with chronic physical disabilities. Soc Sci Med 2009;69:56-60.

31 Vassilev I, Rogers A, Sanders C, et al. Social status and living with a chronic illness: an exploration of assessment and meaning attributed to work and employment. Chronic IIIn 2014;10:273-90.

32 Rozario PA, Morrow-Howell N, Hinterlong JE. Role enhancement or role strain: assessing the impact of multiple productive roles on older caregiver well-being. Res Ageing 2004;26:413-28. 